\title{
Endoscopic extraction of bile duct stones: management related to stone size
}

\author{
A Lauri, R C Horton, B R Davidson, A K Burroughs, J S Dooley
}

\begin{abstract}
Endoscopic sphincterotomy has become the first line treatment for patients with common bile duct (CBD) stones. This technique may fail, however, due to difficult anatomy, previous surgery, periampullary diverticula or the presence of a large stone. The importance of stone size to the success of endoscopic sphincterotomy has not been fully assessed. A prospective study was carried out over the period January 1987 to December 1989 on 100 patients (45 male, 55 female, median age 69 years, range 19-97) with CBD stones in which a policy of early duct clearance was followed. Endoscopic retrograde cholangiopancreatography (ERCP) was performed and the stone size and number recorded from the cholangiograms and corrected for magnification. Sphincterotomy was performed using a diathermy unit with a cutting current and stones were extracted using a balloon catheter or a Dormia basket. Of the 100 patients with CBD stones receiving ERCP, successful clearance of the biliary tree was possible in seven without endoscopic sphincterotomy and five were felt to be unsuitable for endoscopic sphincterotomy. Of the remaining 88 patients endoscopic sphincterotomy was successful in $75(85 \%)$. Of the 75 patients having endoscopic sphinc-
\end{abstract} terotomy stone clearance was successful in $44(59 \%)$. There were no deaths and only four complications, which rapidly resolved on conservative treatment (two acute pancreatitis, two bleeding). The number of CBD stones present was similar in those patients with successful endoscopic sphincterotomy and duct clearance (median 1, range $1-10, n=44$ ) as in those in whom it failed (median 2, range 1-6, $\mathbf{n}=31$ ). In contrast there was a highly significant difference when stone size was analysed (successful clearance median stone size 10 mm, range 3-27 mm; unsuccessful: median 18 $\mathrm{mm}$, range $10-42, \mathrm{p}<0.001)$. Stones less than $10 \mathrm{~mm}$ in diameter $(\mathrm{n}=21)$ were all removed successfully whereas in patients with stones over $15 \mathrm{~mm}(\mathrm{n}=25)$ only three were removed endoscopically (12\%). All patients with evidence of residual stones had additional treatment. Of these 31 patients, 10 had surgery, 11 had insertion of an endoprosthesis, and 10 had dissolution treatment with methyltert-butyl ether through a nasobiliary catheter. This study shows the importance of stone size to the success rate of endoscopic removal of bile duct stones.

(Gut 1993; 34: 1718-1721)

Endoscopic sphincterotomy has become the procedure of choice for patients with common bile duct (CBD) stones. Stones remaining in the gall bladder may be removed, if necessary, by laparoscopic cholecystectomy. ${ }^{12}$ Endoscopic sphincterotomy is achieved in most patients but may fail because of anatomical abnormalities, periampullary diverticula, biliary strictures or previous surgery (for example Billroth II gastrectomy). In $20-30 \%$ of cases endoscopic sphincterotomy is achieved but duct clearance is not confirmed. $^{3-6}$ In others duct clearance may be impossible because of the presence of large stones. It has been suggested that a failure to confirm duct clearance is associated with increased morbidity and mortality ${ }^{5}$ and an active policy of ensuring complete endoscopic duct clearance or considering additional treatment has been adopted by many centres.

The importance of stone size to the successful clearance of the bile duct after endoscopic sphincterotomy has not previously been analysed. A prospective study was therefore carried out to analyse the relation between stone size and outcome of endoscopic sphincterotomy in patients with CBD stones. During the period of this study our policy was to achieve duct clearance at the time of initial hospital admission otherwise patients had additional treatment by surgery, stenting or dissolution treatment.

\section{Patients}

Between January 1987 and December 1989 endoscopic retrograde cholangiopancreatography (ERCP) was performed at the Royal Free Hospital in 100 patients (45 male, 55 female: median age 69 years, range 19-97) with CBD stones. Fifty three patients were jaundiced with right upper quadrant pain. Twelve had pruritus. Thirty two had acute cholangitis and two acute pancreatitis.

\section{Methods}

ERCP

All patients had prophylactic antibiotics (mezlocillin $2 \mathrm{~g}$ intravenously, Bayer, $\mathrm{UK}$ ) and vitamin $\mathrm{K} 1$ ( $10 \mathrm{mg})$ was given if the prothrombin time was abnormal. Topical pharyngeal anaesthesia was used (Lignocaine $10 \%$ spray) and intravenous sedation (diazepam 5 to $20 \mathrm{mg}$ ) and analgesia (pethidine 50 to $100 \mathrm{mg}$ as required). Antispasmodic (hyoscine butylbromide 20-40 $\mathrm{mg}$ intravenously) was given once the duodenum had been entered. ERCP was carried out with an Olympus JFT10 or TJF10 duodenoscope and cholangiography performed using iopromide diluted 50:50 with normal saline. Fixed radiographs were obtained and the stone 
size and number recorded. The measured diameter was then corrected for magnification.

\section{SPHINCTEROTOMY}

Endoscopic sphincterotomy was done by two endoscopists (JSD and AKB) using a Zimmon sphincterotome and an Olympus PSD-2 diathermy unit. A precutting or needle knife was not used. The length of sphincterotomy made was based on the size of stone to be extracted and the anatomy of the papilla and suprapapillary fold. Stones were extracted with a balloon catheter or a Dormia basket. Patients with large stones that could not be removed after endoscopic sphincterotomy had a nasobiliary drain inserted. If duct clearance was not confirmed at the time of endoscopic sphincterotomy, a follow up ERCP was performed within three to four days.

\section{ADDITIONAL TREATMENT}

All patients who did not have complete endoscopic clearance of CBD stones at initial hospital admission were considered for additional treatment. Patients in this group were referred for surgery if they were considered to be fit for anaesthesia. The remaining patients either had insertion of a nasobiliary catheter and dissolution treatment with methyl-tert-butyl-ether (MTBE) or endoscopic insertion of an endoprosthesis. These last two approaches represented part of a historical progression. In the early stages of the study the use of MTBE was being investigated ${ }^{7}$ whereas later in the study stenting was the treatment of choice for this group of patients.

\section{ANALYSIS OF OUTCOME}

Patients were considered to have successful endoscopic stone removal only if there was cholangiographic confirmation of common duct clearance during the initial hospital admission. The success of stone removal after endoscopic sphincterotomy was analysed according to the size and number of CBD stones. Follow up information on patients in whom stone removal was not successful by endoscopic sphincterotomy and who had surgery, stenting or dissolution treatment with MTBE was obtained by reference to case notes and by consultation with their general practitioners. Statistical compari-

Figure 1: Management of 100 patients presenting with common bile duct stones.

$E S=$ endoscopic sphincterotomy.

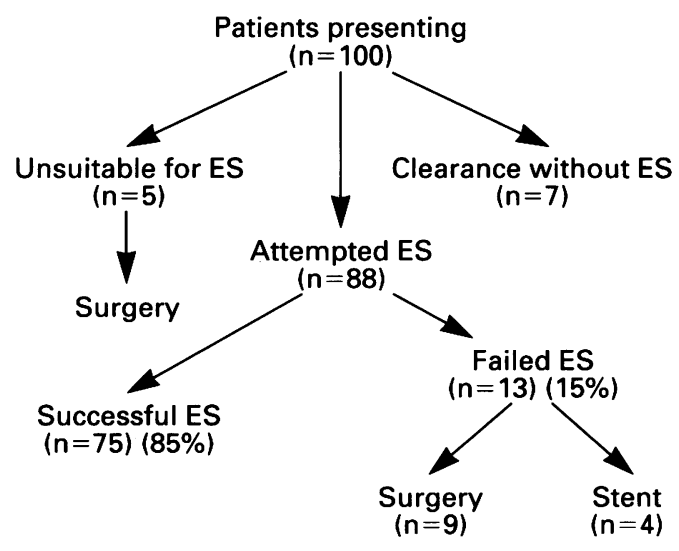

son between groups was carried out by an unpaired $t$ test.

\section{Results}

Of the 100 consecutive patients with CBD stones, successful clearance of the biliary tree was possible without a sphincterotomy in seven patients. In three the stones passed spontaneously without endoscopic sphincterotomy, three had previously had endoscopic sphincterotomy, and in one patient a soft stone disintegrated when the catheter was passed up the bile duct. Of the remaining 93 patients five were referred for surgery without an attempt at endoscopic sphincterotomy. This included two patients whose history and signs suggested acute cholecystitis, one with a single stone of $30 \mathrm{~mm}$ diameter, one with a CBD packed with stones, and one patient with Mirizzi syndrome. Endoscopic sphincterotomy was attempted in the remaining 88 patients and was successful in 75 (85\%). Endoscopic sphincterotomy failed in 13 patients due to duodenal diverticula $(n=4)$, previous Billroth II gastrectomy $(n=1)$, biliary stricture $(n=1)$, and other anatomical reasons $(\mathrm{n}=7)$ (Fig 1).

Of the 75 patients in whom endoscopic sphincterotomy was performed (Fig 2) stone extraction and clearance of the common bile duct was successful in 44 (59\%). Duct clearance was achieved in 30 patients at the first session, 13 at a second, and one at a third. The remaining 31 patients subsequently had surgery $(n=10)$, endoprosthesis insertion $(n=11)$ or dissolution treatment with MTBE through a nasobiliary catheter $(n=10)$.

In this group of 75 patients the number of CBD stones per patient varied from one to 10 with a median of two. The diameter of the largest stone varied from $3-42 \mathrm{~mm}$ with a median value of $12 \mathrm{~mm}$ (Fig 3). A comparison of patients with successful stone clearance by endoscopic sphincterotomy (median 1 , range $1-10, n=44$ ) with those in whom it was unsuccessful (median 2 , range $1-6, n=31$ ) showed no significant difference in stone number. There was, however, a highly significant difference with regard to stone size (successful: median $10 \mathrm{~mm}$, range 3-27; unsuccessful: median $18 \mathrm{~mm}$, range 10-42 $\mathrm{mm}, \mathrm{p}<0.001$ ) (Fig 4). Of the patients with stones over $15 \mathrm{~mm}(\mathrm{n}=25)$ only three were removed successfully by endoscopic sphincterotomy (12\%). Of patients with stones $<10 \mathrm{~mm}$ all were successfully removed by endoscopic sphincterotomy.

After endoscopic sphincterotomy there were no deaths or complications requiring surgery. Four of 75 patients $(5 \cdot 3 \%)$ had early complications (two acute pancreatitis; two blood loss requiring transfusion) but all made an uneventful recovery.

Dissolution treatment was used in 10 patients in whom endoscopic sphincterotomy had been carried out but CBD stones could not be removed. This was successful in seven patients. The three failures were a result of a failure of dissolution in two and to the side effect of the MTBE in one. These patients went on to be successfully treated by surgery, endoscopic 


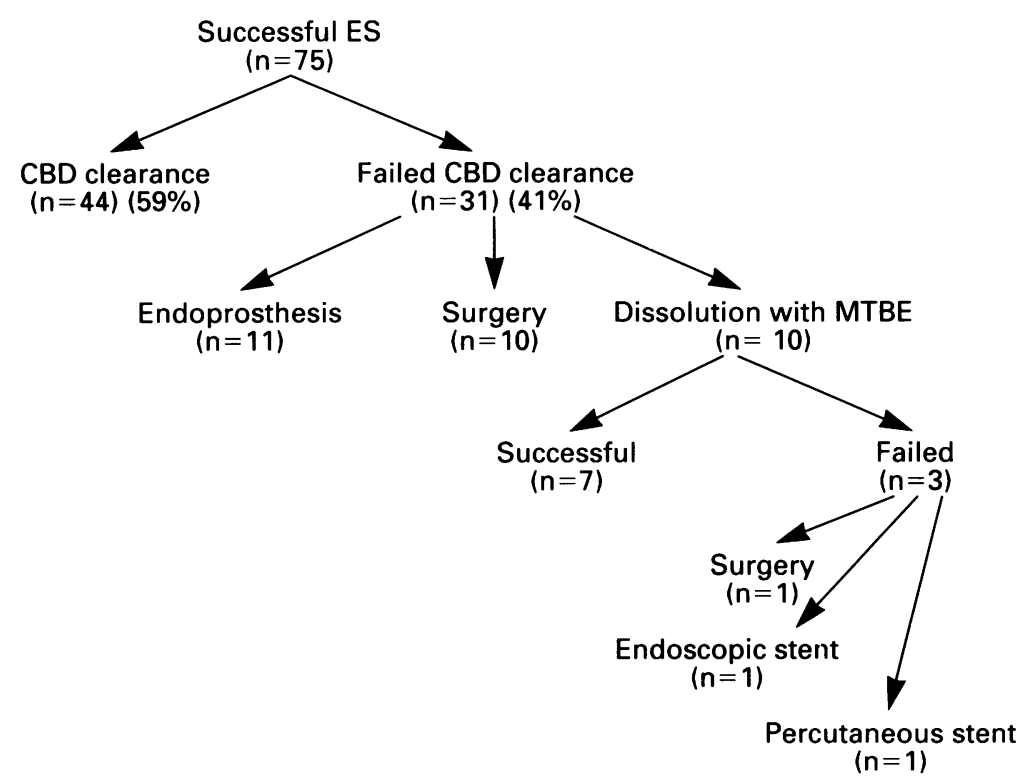

Figure 2: Outcome of 75 patients after successful endoscopic sphincterotomy $(E S) . C B D=$ common bile duct: $M T B E=$ methyl-tert-butyl-ether.

stenting, and percutaneous stenting (one each).

Overall, 24 patients had surgery (14 without endoscopic sphincterotomy, 10 after). The median age of the surgical group was 70 years (range 39-90). There were no operative or postoperative deaths and no complications.

An endoprosthesis was inserted in 15 patients (four without endoscopic sphincterotomy, 11 after). The median age of this group was 83 years (range 60-97). The stone size in this group ranged from $10-42 \mathrm{~mm}$ with a median of $17 \mathrm{~mm}$. Over a minimum follow up period of three years none have died as a consequence of their CBD stones.

\section{Discussion}

The importance of stone size to the success of endoscopic sphincterotomy and duct clearance has not been adequately assessed. Our study clearly shows that stones less than $10 \mathrm{~mm}$ will be safely and successfully removed by endoscopic sphincterotomy and this should therefore be the procedure of choice for small stones. Large stones, over $15 \mathrm{~mm}$, were removed in only $12 \%$ of patients by endoscopic sphincterotomy suggesting that additional or alternative forms of treatment should be considered at an early stage in patients with stones of this size. Other groups have reported similar difficulties with large stones. Silvis suggested that stones larger than $20 \mathrm{~mm}$ were beyond the size of a safe sphincterotomy ${ }^{8}$ while others have suggested that stenting should be used with stones over $15 \mathrm{~mm} .{ }^{910}$

The success of duct clearance after endoscopic sphincterotomy in this series was $59 \%$, which is lower than the $70-80 \%$ reported from some other centres..$^{3-6}$ This may reflect our policy of considering surgery, dissolution or stenting if duct clearance was not confirmed at the initial hospital admission. Allowing a time period after endoscopic sphincterotomy for spontaneous passage of duct stones probably results in higher clearance rates but may have a higher morbidity and mortality. These two management options have not been directly compared. Other explanations for a lower rate of duct clearance in our series include the size of stones, the length of sphincterotomy performed, and the lack of an efficient mechanical lithotripter. In this study one third of all patients had stones of $15 \mathrm{~mm}$ diameter or greater, the size suggested by Kiil ${ }^{9}$ and Moss $^{10}$ as requiring the insertion of a biliary stent. Unfortunately, the studies reporting higher duct clearance rates $^{3-6}$ have not analysed or reported the diameter of the stones in their patient group. The length of the sphincterotomy influences the size of stone that can be removed and the differences in clearance rates may be explained by the use of a shorter sphincterotomy. A larger endoscopic sphincterotomy, however, is probably associated with a higher incidence of complications. In this study there was no deaths and a complication rate of only $5 \%$ (four patients), none of whom

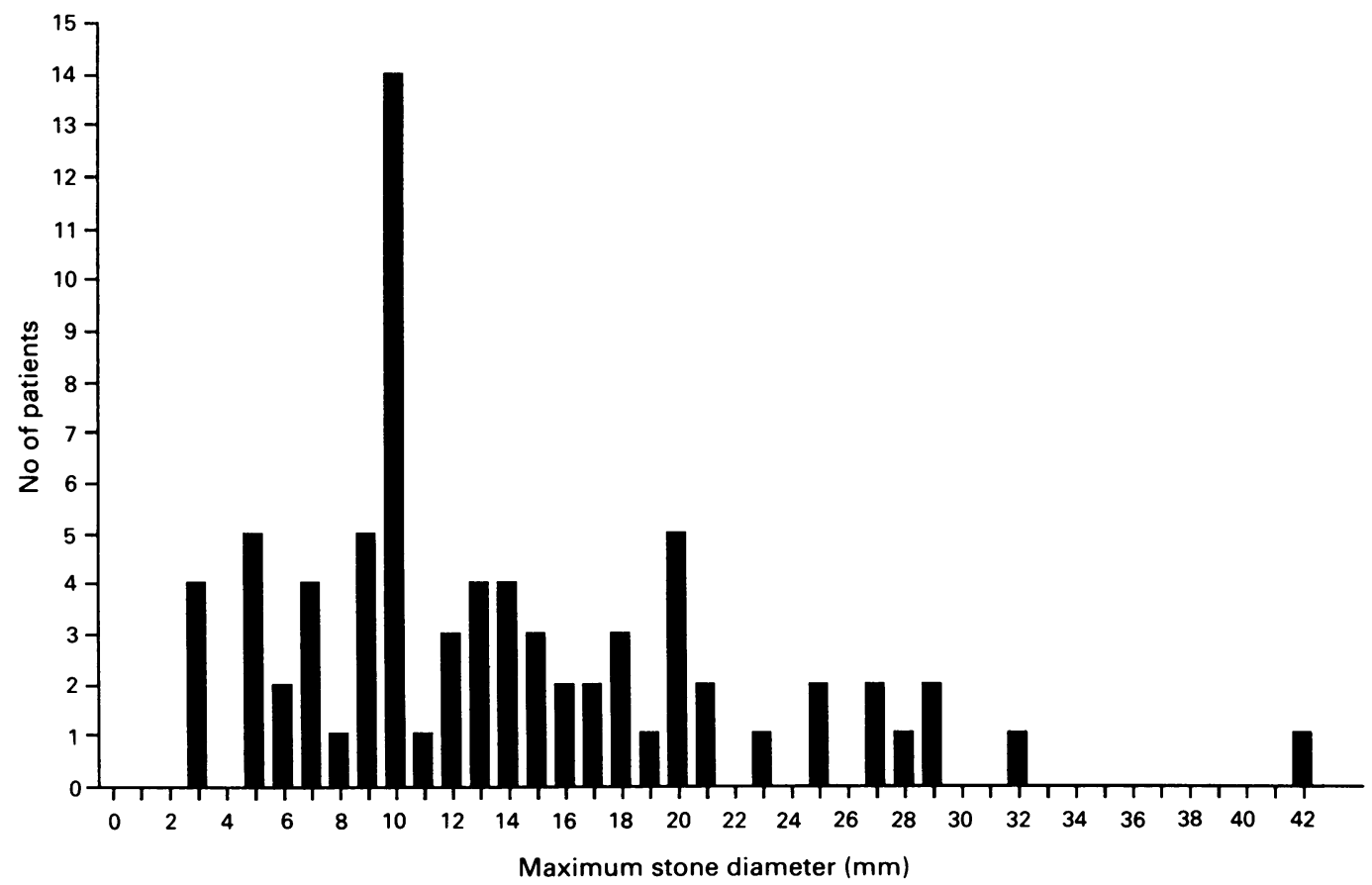



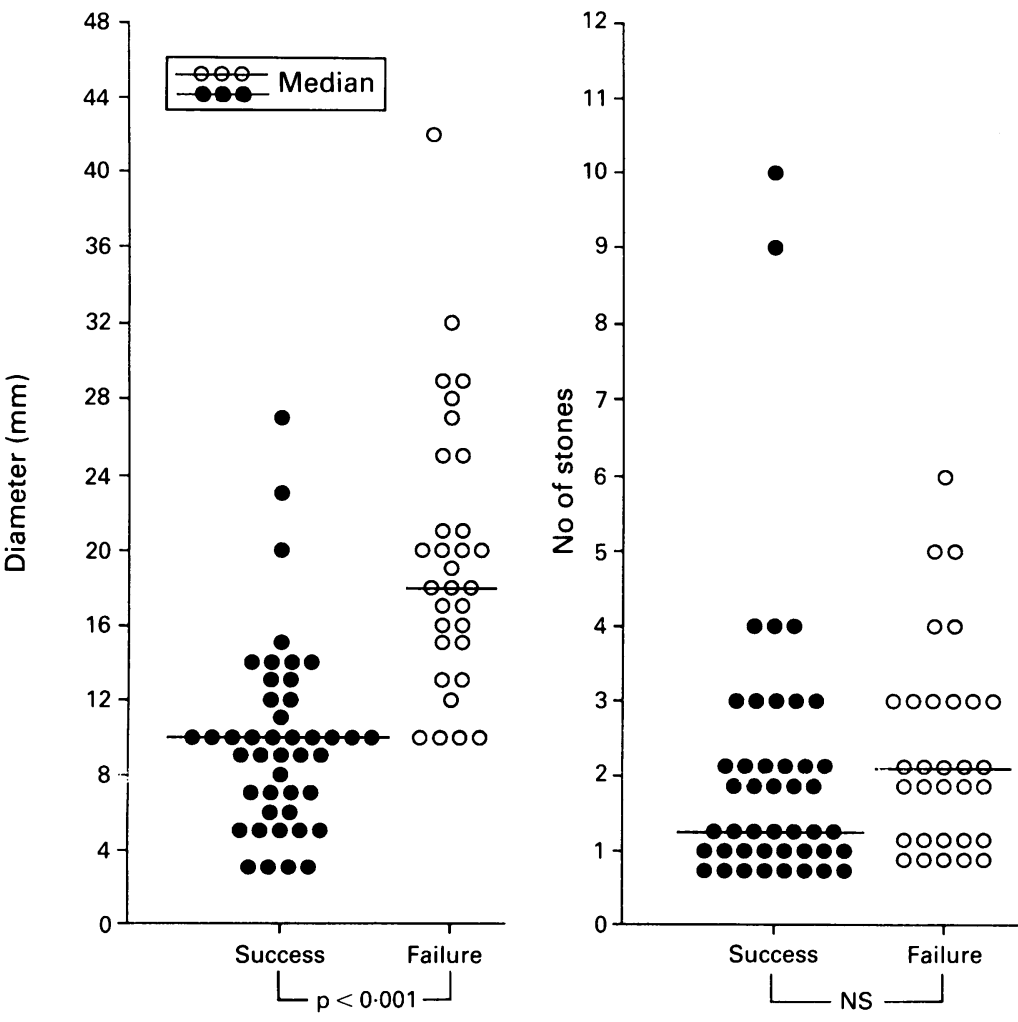

Figure 4: Duct clearance related to stone size and number. required surgery. This compares well with complication rates of $20-30 \%$ from centres whose reported clearance rates are higher. ${ }^{3-6}$ This would suggest that long sphincterotomies should not be used for large stones but that alternative methods should be considered such as mechanical lithotripsy, " surgery, stenting or dissolution treatment if the morbidity and mortality of these procedures is lower. At the time of this study a reliable mechanical lithotripter was not available.

Surgery was performed on 24 patients (14 without and 10 after endoscopic sphincterotomy) with no death and no significant complications. This supports the previous suggestion that the results of endoscopic sphincterotomy and surgery are equally good in healthy patients with CBD stones. ${ }^{4}$ With the advent of laparoscopic cholecystectomy most patients would opt if possible for duct clearance by endoscopic sphincterotomy followed by laparoscopic surgery. This should not, however, be used to justify an extensive and potentially dangerous sphincterotomy in patients with large CBD stones.

Endobiliary stenting was used in 15 patients whose median stone diameter was $17 \mathrm{~mm}$ and who were at high risk for an operative procedure. In common with other groups the results in the short term were satisfactory..$^{9}$

Dissolution treatment has been used in 10 patients and was successful in $7(70 \%)$. This success rate compares favourably with a national survey that reported $\mathrm{MTBE}$ as contributing to duct clearance in only $36 \%$ of cases. The multicentre study, however, included 10 units with very variable success rates, which would suggest that patient selection and the technique are crucial. ${ }^{13}$ The procedure is, however, time consuming and therefore only practical for patients with CBD stones who are unfit for surgery. The procedure has not been compared prospectively with stenting in patients where duct clearance failed after endoscopic sphincterotomy.

Other techniques have been used for the management of large CBD stones that cannot be removed by endoscopic sphincterotomy including extracorporeal shock wave lithotripsy ${ }^{14}$ and laser lithotripsy. ${ }^{15}$ Although these may have a role in some patients with CBD stones they depend upon availability of equipment and expertise to which most endoscopy units will not have access.

We would conclude from this study that for effective treatment of patients with common bile duct stones with the least morbidity and mortality, stone size should be considered along with medical risk factors in selecting the optimum management.

These data were presented in part at the Autumn meeting of the British Society of Gastroenterology, 26-28 September 1990.

We should like to thank the endoscopy unit staff for their assistance and the consultants who referred patients to the Hepatobiliary Unit for investigation.

1 Way LW. Changing therapy for gallstone disease. $N E n g l$ f Med 1990; 323: 1273-4.

2 Cuschieri A, Dubois F, Mouiel J, Mouret P, Becker H, Buess $\mathrm{G}$, et al. The european experience with laparoscopic cholecystectomy. Am $\mathcal{F}$ Surg 1991; 161: 385-7.

3 Escourrou J, Cordova JA, Lazorthes F, Frexinos J, Ribet A. Early and late complications after endoscopic sphincterotomy for biliary lithiasis with and without the gallbladder in tomy for biliary lithiasis with an
situ. Gut 1984; 25: 598-602.

4 Neoptolemos JP, Davidson BR, Shaw DE, Lloyd D, CarrLocke DL, Fossard DP. Study of common bile duct exploration and endoscopic sphincterotomy in a consecutive series of 438 patients. BrF Surg 1987; 74: 916-21.

5 Davidson BR, Neoptolemos JP, Carr-Locke DL. Endoscopic sphincterotomy for common bile duct calculi in patients with gall bladder in situ considered unfit for surgery. Gut 1988; 29: 114-20.

6 Hansell DT, Millar MA, Murray WR, Gray GR, Gillespie G. Endoscopic sphincterotomy for bile duct stones in patients with intact gallbladders. BrF Surg 1989; 76: 856-8.

7 Kaye GL, Summerfield JA, McIntyre N, Dooley JS. Methyl tert butyl ether dissolution therapy for common bile duct

8 Silvis S, Siegel J, Hughes R, Keton R, Sievert C, Sivak M. Use of electrohydraulic lithotripsy to fracture common bile duct stones. Gastroenterology 1986; 32: 155-6.

9 Kiil J, Kruse A, Rokkjaer M. Large bile duct stones treated by endoscopic biliary drainage. Surgery 1989; 105: 51-6.

10 Moss JG, Saunders JH, Wild SR. Endoscopic papillotomy for removal of common bile duct stones without cholecystectomy. F $R$ Coll Surg Edinb $1985 ; 30$ : 112-4.

11 Classen M, Hagenmuller F, Knyrim K, Frimberger E. Giant bile duct stones - non surgical treatment. Endoscopy 1988; 20: 21-6.

12 Cotton PB, Forbes A, Leung JWC, Dineen L. Endoscopic stenting for long term treatment of large bile duct stones: stenting for long term treatment of large bile duct stones:

13 Neoptolemos JP, Hall C, O'Connor HJ, Murray WR, CarrLocke DL. Methyl-tert-butyl-ether for treating bile duct Locke DL. Methyl-tert-butyl-ether for treating bile duct
stones: the British experience. Br F Surg 1990; 77: 32-5.

14 Richter JM, Weinstein DF. Extracorporeal shock wave lithotripsy of common bile duct stones. Gastroenterology 1989; 96 : $252-4$

15 Ell C, Lux G, Hochberger J, Muller D, Demling L. Laser lithotripsy of common bile duct stones. Gut 1988; 29: 746-51. 